\title{
ELECTROMYOGRAPHIC STUDIES ON REFLEX ACTIVITY OF THE INTERCOSTAL AND ABDOMINAL MUSCLES IN CERVICAL CORD LESIONS
}

\author{
L. Guttmann, C.B.E., M.D., F.R.C.P., F.R.C.S., and \\ J. R. Silver, M.B., B.S., M.R.C.P.E. \\ National Spinal Injuries Centre, Stoke Mandeville Hospital, \\ Aylesbury, Buckinghamshire
}

Patients who have sustained a transection or other severe injury of the cervical cord, resulting in a complete lesion, are deprived of the use of such important respiratory muscles as the intercostals and abdominals. In the early stages, this constitutes a serious hazard, as their ability to ventilate depends almost entirely upon the diaphragm. However, in due course, accessory respiratory musclesparticularly the sternomastoid and trapezius-increase in strength and by exerting an upward pull upon the sternum can improve the ventilatory capacity of the tetraplegic patient by increasing the anteroposterior diameter of the chest.

Gilliatt et al (1947) found, in later stages of tetraplegia in a patient with a complete lesion below C6, a vital capacity of 2.8 litres and an inspiratory capacity of $2 \cdot 2$ litres measured while the patient was sitting in a wheelchair. This capacity of the lungs was found to be sufficient to ensure adequate ventilatory function during his daily activities, including playing table tennis.

Cameron et al. (1955) studied the effect of posture on the vital capacity of II tetraplegic patients; they found that it was only 65 per cent. of a predicted normal (calculated from the weight and height of the patient), when examined with the patient supine, but that it could be increased by strapping the patient to a tilting table and tilting his head down $15^{\circ}$. Conversely, it was decreased by elevating the head $15^{\circ}$ above the horizontal. They attributed these postural effects to the paralysis of the abdominal muscles, which allowed the intestines to bulge through the flaccid abdominal wall, the diaphragm thus assuming a lower position in the chest and having a smaller excursion.

Talbot et al. (I957) studied I 8 tetraplegic patients. They found a similar reduction in the vital capacity, and there was a proportionate reduction in the inspiratory and expiratory reserve volumes. The maximum breathing capacity and the one-second forced expiratory volume were both at the lower limit of normal, the reduction being in proportion to the fall in the vital capacity. In the same year, Wingo (I957) assessed the vital capacity in 20 tetraplegics by three different methods and found that all three gave similar results.

Hemingway et al. (I958), in a comprehensive paper on the pulmonary function of paraplegic patients, found that in a group of tetraplegic patients the vital capacity was approximately two-thirds of normal and the maximum breathing capacity half of normal. They were surprised at the magnitude of the ventilatory capacity which this group of patients had maintained, since they only had inspiratory muscle function.

The activity of the respiratory muscles-especially intercostals and abdominals 
-in the act of breathing has been a subject of research for many years, and in the last 30 years workers in this field, such as Anderson and Lindsley (I935), Bronk and Ferguson (1935), Campbell and Green (1953) and Campbell (1952, I955), have reported electromyographic observations on the function of these muscles in man and animals under normal and pathological conditions. However, the literature on electromyographic studies of the respiratory muscles following transection of the cervical cord in man is still scanty.

Grossiord et al. (1963) studied the actions of the shoulder girdle and abdominal muscles during breathing in a group of tetraplegic patients, using a combination of spirometry and electromyography. They confirmed that the shoulder girdle muscles contracted during expiration.

There is now general agreement that the diaphragm, sternomastoid and trapezius are the most important respiratory muscles in the tetraplegic. However, in a previous publication by one of us (Guttmann \& Bell, I958), the question was raised whether and to what extent the paralysed intercostal and abdominal muscles participate by reflex action in the act of breathing, since they regain their tone when the stage of spinal shock has subsided and the cord has regained its automatic function. Therefore, it seemed worth while to investigate this possibility in detail, and in the present paper an account is given of electromyographic studies of this problem in tetraplegic patients during various stages following cervical cord transection.

\section{CLINICAL MATERIAL}

A total of I9 patients with initially complete lesions of the cervical cord at levels between $\mathrm{C}_{4}$ and $\mathrm{C} 8$ segments, following fracture dislocation of the cervical spine, were examined. Their ages were between 17 and 60 years. There were I7 men and 2 women. They can be conveniently divided into three groups:

Group I consists of four patients with complete transverse spinal cord syndromes of the mid-cervical cord, examined in the initial stage after injury, the first electromyographic test being carried out between one and eight days after injury. Table I shows the clinical details-i.e. the state of the tendon reflexes and plantar responses in relation to the vital capacity and the electromyographic findings. The electromyographic examinations in these cases were repeated at various intervals, until the stage of spinal shock had subsided and full reflex activity of the isolated cord had developed, and were continued up to a minimum of 78 days and a maximum of 197 days.

Group 2 consists of ro patients first examined in later stages of traumatic tetraplegia. The interval between the date of injury and the first electromyographic examination varied between three months and more than four years. In all these patients full reflex activity of the isolated cord below the level of the lesion was established, as shown by the increased reflex function of the skeletal muscles, bladder and intestines.

Group 3. In five tetraplegics, electromyographic studies of the intercostals were carried out in relation to X-ray studies of the diaphragm. Two subjects (with initially complete transverse spinal syndromes which showed some functional recovery in due course) were first examined electromyographically three and four days respectively after injury, during the stage of spinal shock, and followed up 
for $7 \mathrm{I}$ and 9I days respectively. The three other subjects were first examined one and a half to five months after injury, after full reflex activity of the isolated cord had recovered.

\section{RECORDING SYSTEM}

The amplifier-recording system was an Ediswan 6-channel electroencephalograph with ink-writers. Each amplifier had a push-pull input with 2 resistance-capacitance coupled stages and two final direct-coupled stages. The gain was adjusted to give a pen deflection of about 100 microvolts per $\mathrm{cm}$. The time constant was set at $.03 \mathrm{sec}$. and the high frequency loss of 15 per cent. at a setting of 500 c.p.s. or 5000 c.p.s. Respiratory recordings were made by a spirometer of a six-litre water-filled Palmer lung-volume type. The patient was attached to this by wide-bore rubber tubing $2.5 \mathrm{~cm}$. in diameter; a gagtype mouthpiece was placed between his teeth and a nose clip was placed on his nose. The spirometer was placed opposite the electromyograph and a thread from its pulley wheel was passed across the recording paper of the electromyograph to another pulley wheel. This thread was attached to the weighted writer-point which moved between $\mathrm{I} \mathrm{cm}$. and $2 \mathrm{~cm}$. ahead of the electroencephalograph pens. A correction of this amount had to be made when interpreting the records. Figure I shows the subject (M.J.H.O.)

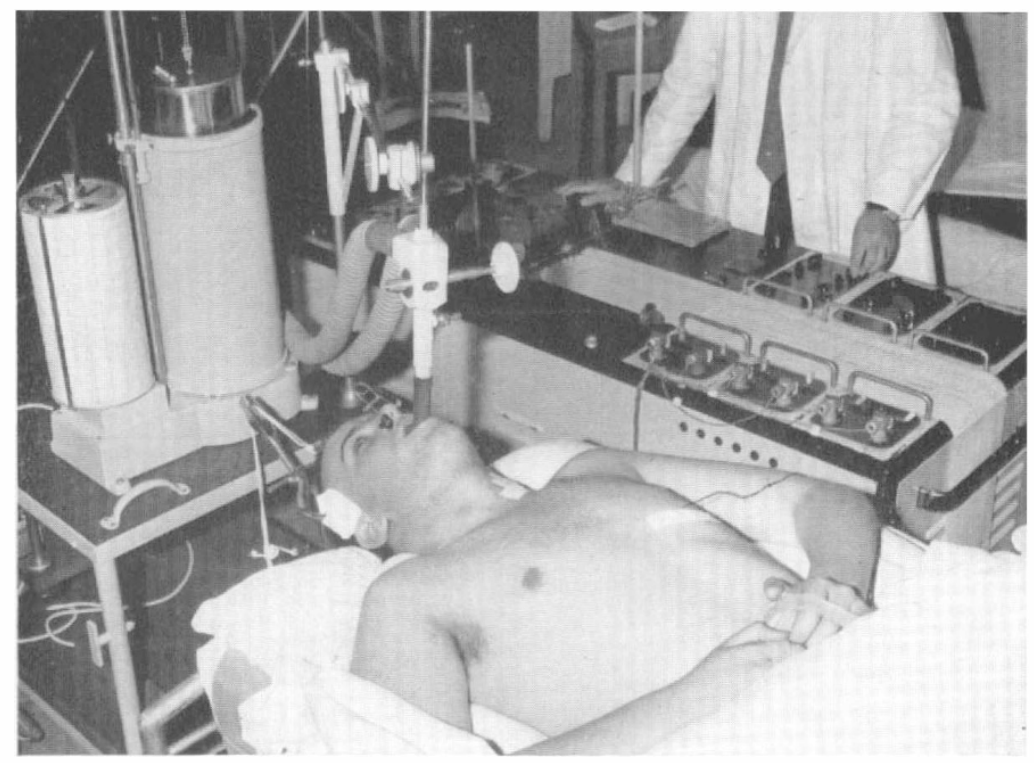

FIG. I

M. J. H. O., being examined within the first few days of injury. Note the skull traction apparatus and that the pen of the respiratory recording is writing a few centimetres ahead of the electromyographic pens.

being examined within the first few days of injury. At a later stage in our research, we obtained a Medelec oscilloscope, which enabled us to carry out more detailed studies on the localisation and identification of the action potentials of the intercostal muscles to be examined. 
TABLE I

Details of Four Patients examined within Eight Days of Injury

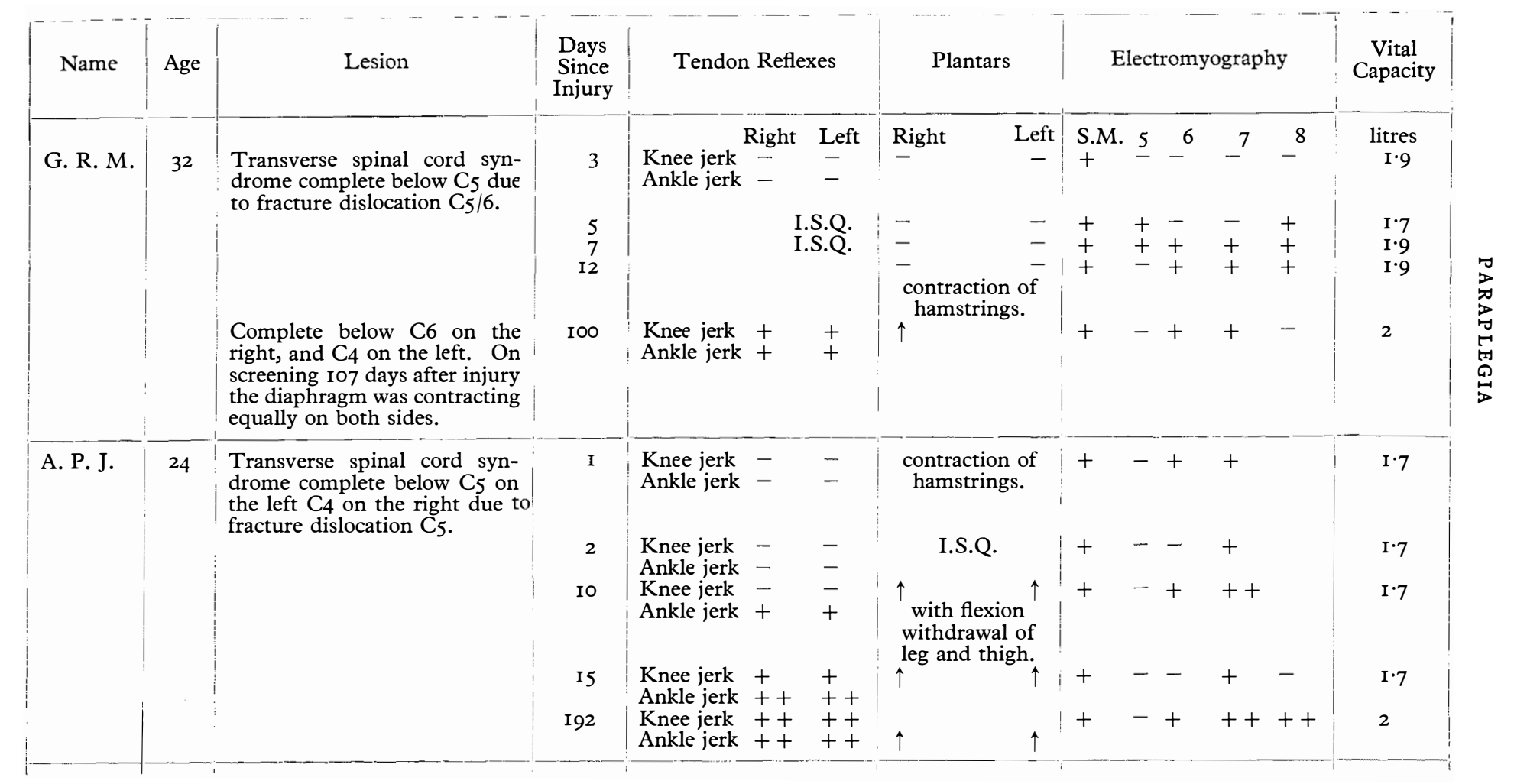




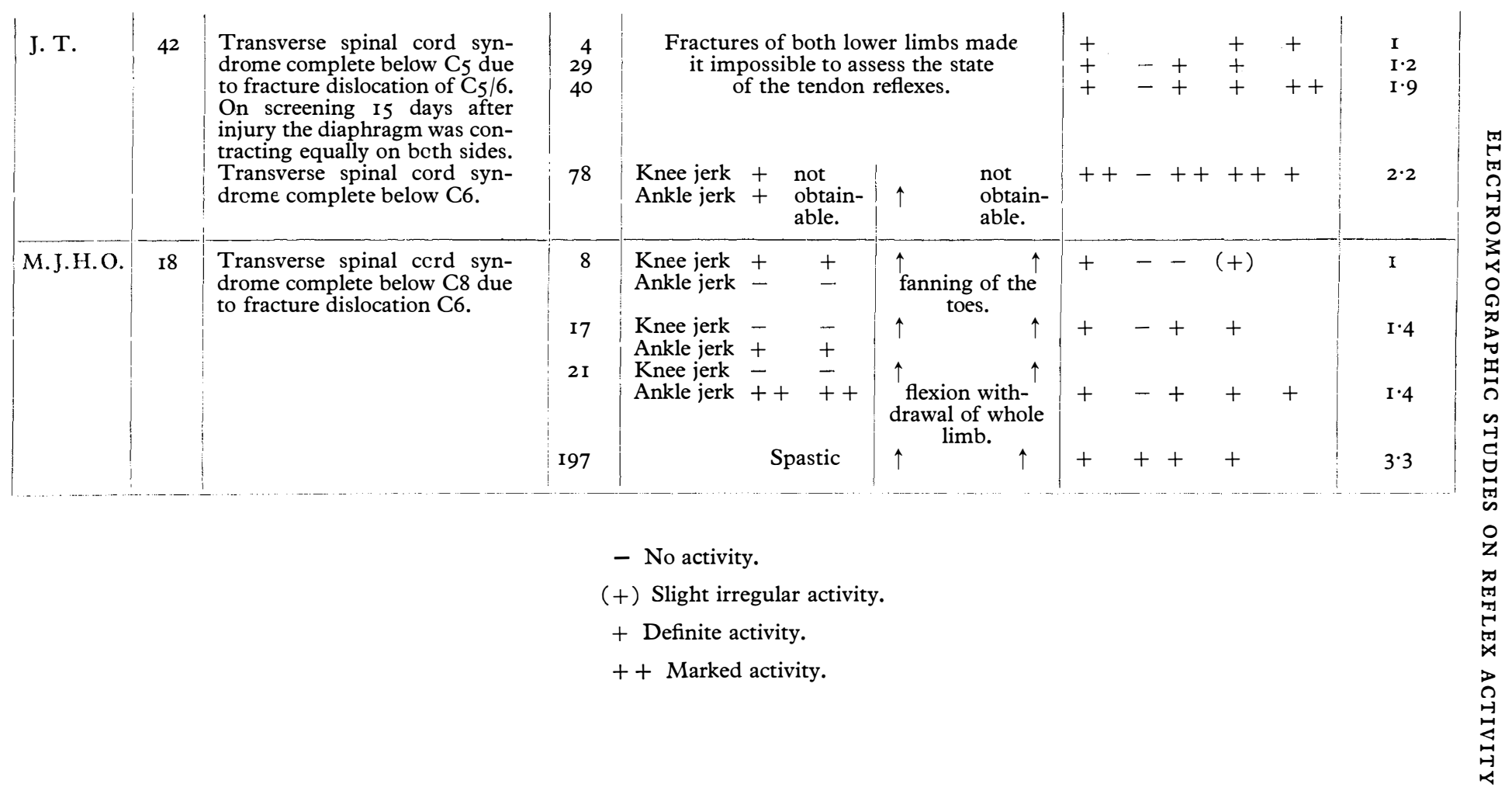




\section{EXPERIMENTAL PROCEDURE}

The method described by Campbell (1958) of examining the respiratory muscles in normal subjects was closely followed in this study. It was decided to use surface electrodes initially to discover if there was activity in sternomastoid, intercostal or abdominal muscles, but in a limited number of patients concentric needle electrodes were also used. The patients were examined lying in the supine position in a separate room, so that there would be no disturbance of the respiratory rhythm by extraneous noise or stimuli. The experiments were repeated on different days, and care was taken to limit the study to not longer than two hours because of the danger of the patients developing pressure sores from lying too long in the same position. Calibration of the EEG machine was carried out before and after each experiment at all gain settings used, and this calibration was repeated several times during an experimental run. The spirometer tracing was also calibrated so that the vital capacity could be measured. This reading was then corrected to B.T.P.S. Circular silver surface electrodes were used, $12 \mathrm{~mm}$. in diameter with a rim of $2 \mathrm{~mm}$. and a central shallow cup. The skin was carefully prepared by cleaning it first with ether and then with an abrasive electrode jelly. The cups were filled with electrode jelly, applied firmly to the skin and fixed with adhesive plaster to prevent detachment due to spasm and excessive sweating, which may occur in later stages of tetraplegia in some of these patients. Pairs of electrodes were applied $2 \mathrm{~cm}$. apart and one earth electrode was used; the siting of the latter was not found to be important. Electrodes were first applied to the sternomastoid muscle. The patient's position was then adjusted until there was no activity at rest. The patient was then asked to breathe deeply and to carry out some voluntary activity, such as turning his head or shrugging his shoulders. When a satisfactory record had been obtained from the sternomastoid muscle it served as a check on the timing of any respiratory activity detected in other muscles, since the sternomastoid, being innervated by the accessory nerve, has a normal nerve supply.

The 2 nd, 3 rd, 4 th, 5 th, 6 th, 7 th and 8 th intercostal spaces were then examined and electrodes were also placed at various sites on the abdomen. The most marked motor activity in the intercostal spaces was found anteriorly, by placing the electrodes II-I $3 \mathrm{~cm}$. from the midline. The activity decreased progressively as the electrodes were placed further back.

The abdominal muscles were explored by the same technique, using surface electrodes. Activity was found most readily over the external oblique muscle at the level of the umbilicus between $5-14 \mathrm{~cm}$. from the midline, but it frequently required maximum breath to evoke this, in contrast to the activity in the lower intercostal spaces where a breath as small as 0.5 litre could elicit activity.

In order to localise more accurately the source of activity of the intercostal muscles detected with the surface electrodes, concentric needle electrodes were used which were placed beneath or adjacent to the surface electrodes in the lower intercostal spaces. This was studied in four patients who had already been examined extensively with surface electrodes. In two of the subjects, the activity of the intercostal muscles was recorded by the Medelec oscilloscope. It was found that, when the needle was situated in the muscles, marked activity could easily be elicited during inspiration, while withdrawal of the needle by only one millimetre resulted in diminution of activity, which ceased altogether even to deepest inspiration when the needle was lying in the subcutaneous tissue. When the needle was advanced too far, touching the pleura, the subject invariably complained of pain in the tip of the shoulder. The technique employed with the Medelec oscilloscope was the same as that employed with the EEG machine. An earth electrode was placed on the subject's arm and activity was recorded in the sternomastoid muscle, with surface electrodes to serve as a time marker; the lower intercostal spaces were then explored with both surface and needle electrodes. Once well-marked activity had been detected, films were taken. Several different speeds were employed; firstly the film was run slowly at I or 2.5 inches per second to show the pattern of intercostal activity in relation to the 
sternomastoid contraction, and then with the needle in situ the speed of the film was increased to Io inches per second to demonstrate the actual wave form.

Figure 2 demonstrates a comparison between needle and surface electrodes, depicting intercostal activity in the 8th right interspace $13 \mathrm{~cm}$. from the midline, in a case of traumatic tetraplegia below $\mathrm{C} 5$, seven months after injury. The intercostal activity elicited during inspiration is definitely more clearly seen in the record of the needle electrode.

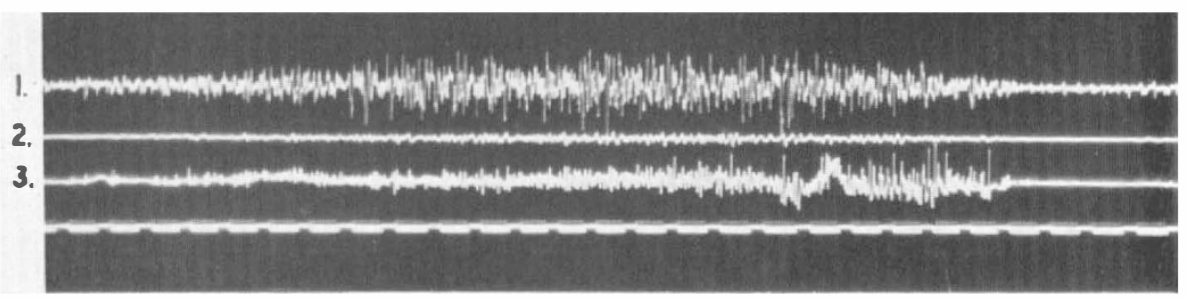

FIG. 2

I. C., 7 months after complete lesion below $\mathrm{C}_{5}$.

Lead (I) right sternomastoid muscle (surface electrodes).

Lead (2) 8 right intercostal space $13 \mathrm{~cm}$. from the midline (surface electrode).

Lead (3) 8 right intercostal space $15 \mathrm{~cm}$. from the midline (needle electrode).

Paper speed $\mathrm{I}$ inch per second. Calibration in all leads IOO $\mu \mathrm{v}$. Response to a deep breath.

This shows that the activity is more marked with needle than with surface electrodes.

\section{ANALYSIS OF THE RECORDS}

The activity associated with each of the procedures was classified as follows:

I. No activity.

2. Slight activity not related to the test stimulus.

3. Definite activity related to the test stimulus.

4. Marked activity which could be detected with considerably reduced amplification.

Little difficulty was found in assigning the activity to one of the preceding groups, and where any doubt existed the activity was ignored. The analysis of the records was quite easy as the paralysed muscles were not under voluntary control and, therefore, there was a striking absence of any extraneous voluntary activity. The only interference encountered was the ECG; further artefacts were due to poor or variable contact of the electrodes and occasional flexor spasms; the latter could often be detected on all leads.

\section{RESULTS}

Group I: Early Stages. Table I illustrates the relationship of the reflex activity in the lower limbs, during the stages of spinal shock and later stages of tetraplegia, to the electromyography and vital capacity.

At the initial electromyographic examination on the four subjects, difficulty was experienced in detecting activity in the sternomastoid muscle despite the fact that it was normally innervated. Its activity was of small amplitude, requiring the maximum breaths which a patient was able to take, and it appeared late in inspiration.

When the intercostal spaces were examined, the difficulty in detecting any activity was even greater. It was necessary to apply the electrodes several times 
to an interspace, with the amplification at its maximum and the patient taking the deepest possible breaths. Even then no activity at all could be found in the 2nd, 3 rd or 4 th interspaces and only little activity was found in the 5 th, 6 th, 7 th and 8 th interspaces; it was localised to one or two spaces anteriorly, and it occurred at the height of the maximal inspiration which the patient could take.

Figure 3 illustrates these points, in the case A. P. J., examined one day after he had sustained a complete lesion below $\mathrm{C}_{4}$ on the right and $\mathrm{C}_{5}$ on the left. However, there was some sign of activity of the isolated cord as revealed by a contraction of the hamstrings on plantar stimulation. The electrodes were placed IO-I $4 \mathrm{~cm}$. from the midline of the body.

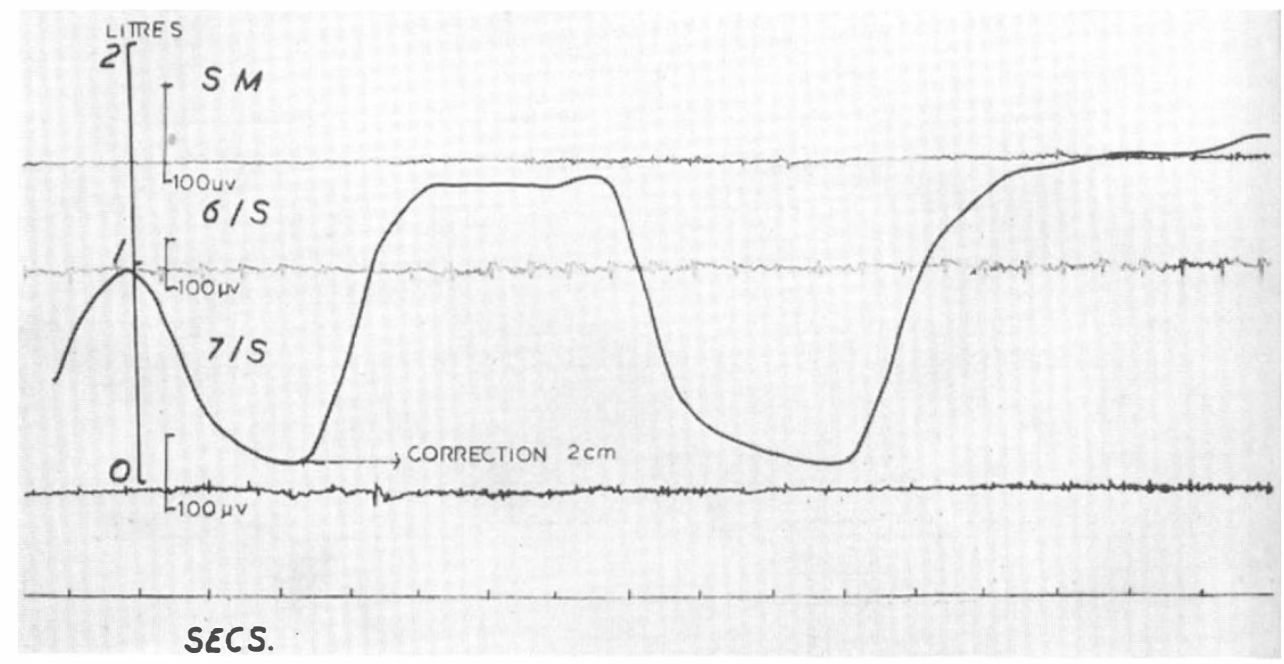

FIG. 3

A. P. J., I day after a complete lesion below $\mathrm{C}_{4}(\mathrm{R}) \mathrm{C}_{5}$ (L). S.M.: Sternomastoid, upper tracing. 6 I.S.: 6th intercostal space, middle tracing. 7 I.S.: 7 th intercostal space, lower tracing. Phasic line is the respiratory tracing, inspiration being an upward deflection. Note the correction which has to be applied in the respiratory tracing since it does not correspond in time with the electromyographic record. There is a little irregular activity in all three leads during inspiration.

As shown in Figure 3, there was very little late inspiratory activity in the sternomastoid and a little irregular activity in the 6th and 7 th interspaces not clearly related to the act of breathing. It may be noted that at this stage the patient could take a breath of over I. 5 litres.

A subsequent electromyographic examination performed Io days after injury, when his ankle jerks were present and the planter responses clearly extensor, showed a slight increase in the activity in the sternomastoid muscle. The most striking feature, however, was the increase in amplitude of the activity found in the 6 th and 7 th interspaces ; it was much larger, particularly in the 7 th space, and in both 6th and 7 th interspaces it was clearly related to the act of breathing, commencing at the beginning of inspiration and lasting until the beginning of expiration. It still required a breath of nearly 2 litres to elicit this activity, while two smaller breaths of less than I litre evoked no activity at all (fig. 4). 
Examination performed 192 days after injury, when he had developed wellestablished reflex function of the isolated cord with markedly increased spasticity below the level of the lesion, showed increased activity in the sternomastoid and both 6th and 7 th interspaces, which could now be elicited by a breath as small as 0.5 litre (fig. 5).

\section{A HELO BREATH}

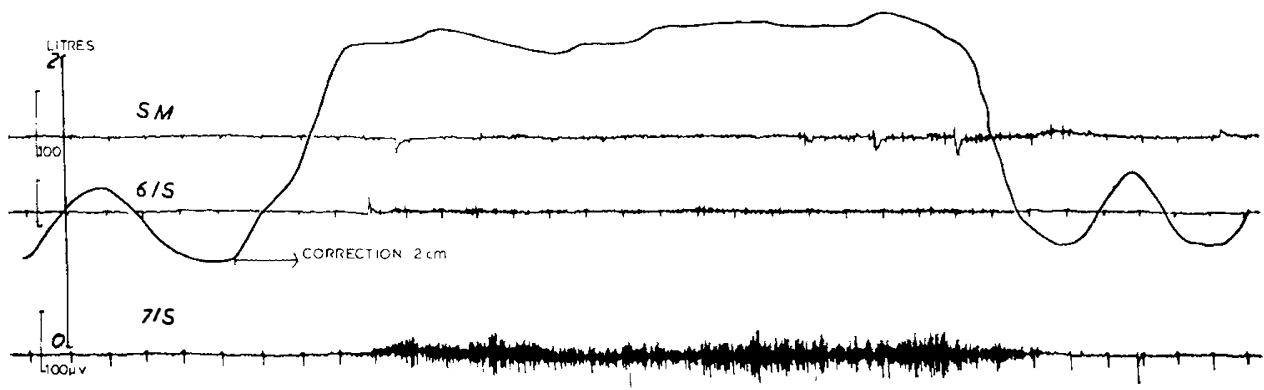

Fig. 4

A. P. J., Io days after injury. Considerable increase in the activity found in the 6th and 7 th interspaces.

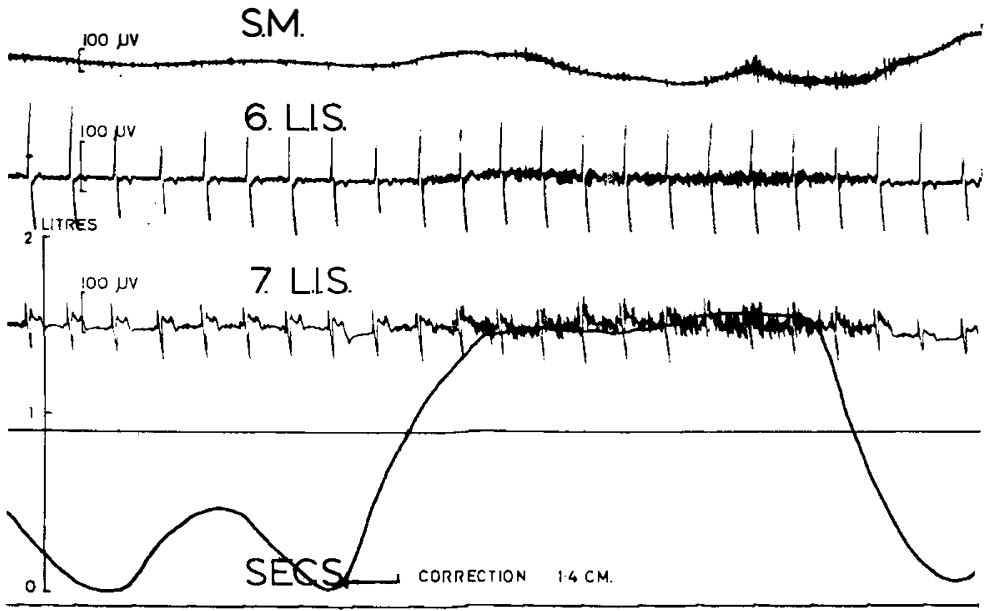

FIG. 5

A. P. J., I92 days after injury. Further increase in the activity, particularly in 6th intercostal space and sternomastoid muscle, and the activity is elicited by a breath of less than 0.5 litre, which in Figures 3 and 4 did not produce any activity. 
Another example of this group is case J. T., a complete lesion below C5/6 (Table I), who was first examined four days after injury (fig. 6).

The activity of the sternomastoid was not well developed, but the activity in the 7 th left and right interspaces, although of small amplitude, was clearly related to breathing (fig. 6). Twenty-nine days after injury there had been no change in his physical signs, but the action potentials in the 7 th left interspace are of longer duration (fig. 7). The function of the sternomastoid was still very small. Seventyeight days after injury, when the tendon reflexes had returned to his right leg (the left was still in plaster) and his right plantar was extensor, there was a striking change in the respiratory activity. Not only had the action potentials during

SM.

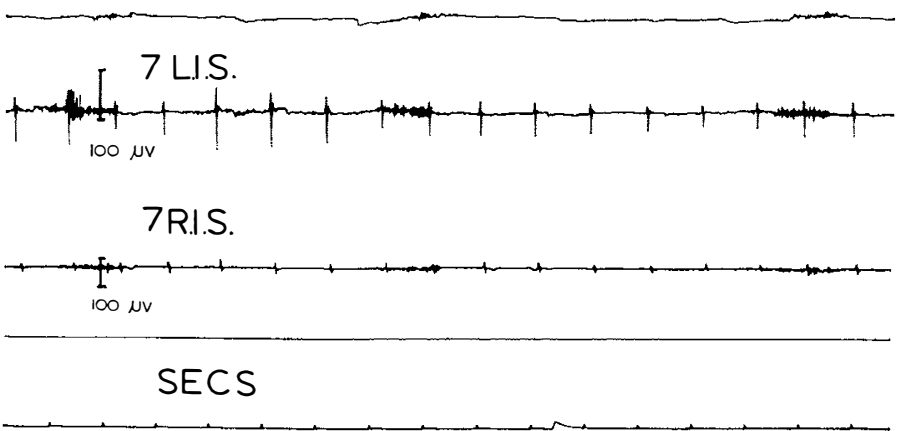

FIG. 6

J. T., 4 days after complete lesion below $\mathrm{C}_{5}$. There is no respiratory tracing, and the timing of the activity in 7 th left and right interspaces (7 L.I.S., 7 R.I.S.) in relation to inspiration may be derived from the sternomastoid which is normally innervated. The activity in intercostal spaces occurs earlier than in the sternomastoid.

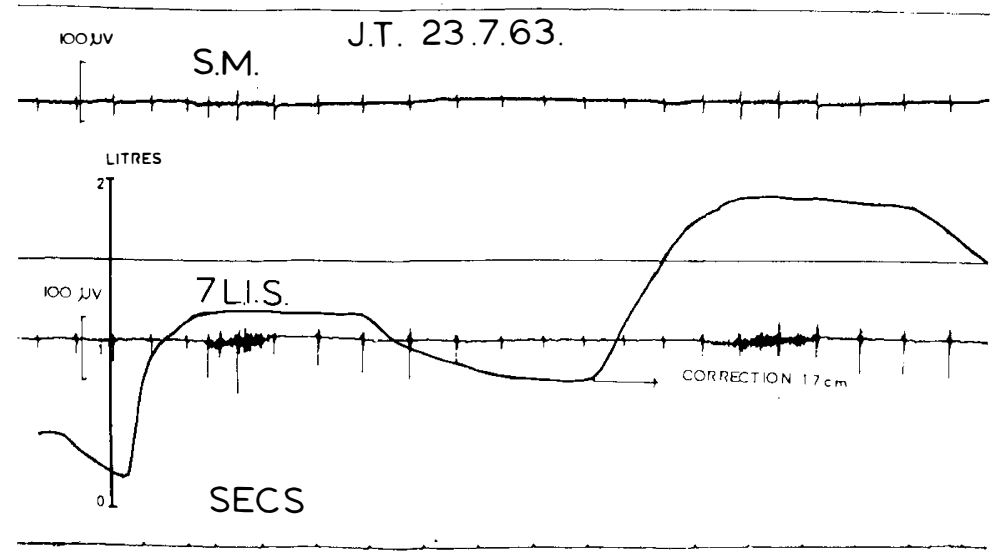

FIG. 7

J. T., 29 days after injury. The activity in 7 th left interspace is of longer duration than that seen in Figure 6. 
inspiration increased in amplitude and duration but they could be elicited by smaller inspiration (fig. 8). An additional further rhythm, though only slight, appeared during early expiration; this seemed to be quite distinct from the inspiratory rhythm and was most marked in the 7 th interspace with breaths of over 2 litres, but it could be seen in the 6th space as well.

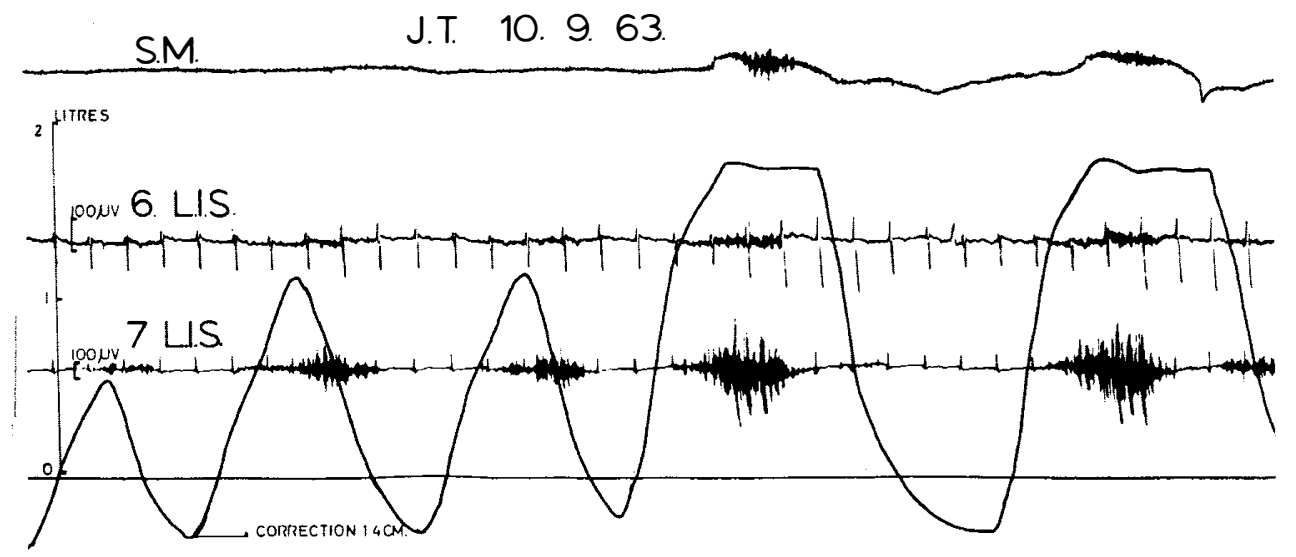

SECS.

Fig. 8

J. T., 78 days after injury. The inspiratory activity in 7 th left interspace has increased in amplitude and duration compared with previous findings. The inspiratory activity increases progressively with deeper breaths. With a breath of over 2 litres a separate expiratory rhythm can be seen.

Group 2: Late Stages. Of the Io tetraplegics examined in later stages, six were examined within the first year after injury, and of these four in the latter half. In the remaining four cases the first electromyographic experiment took place two to four years after injury. In all cases, full reflex activity of the isolated cord was established: the motor paralysis was of spastic type with exaggeration of the tendon reflexes below the level of the lesion, and there was bladder and bowel automatism and complete sensory loss below the level of the lesion which in four cases was below $\mathrm{C}_{5}$, in five below $\mathrm{C}_{6}$, and in one below $\mathrm{C}_{7}$.

In contrast to the electromyographic findings obtained in the four cases during spinal shock and early stage of reflex activity of the isolated cord, the responses of both the intercostals and abdominal muscles in the ro late cases were found to be distinctly larger in amplitude and longer in duration. Moreover, the responses were clearly related to the act of breathing. They could be elicited even by weak stimuli-i.e. quiet breathing-while stronger stimuli markedly increased these responses over a wider area involving also the upper intercostal spaces. In two patients with greatly increased reflex activity of the isolated cord, a close relationship between flexor spasms of the legs and reflex responses of the respiratory muscles was found. This could be elicited by plantar stimulation of the feet; conversely deep inspiration could elicit flexor spasm of the legs. 
The reflex responses of the intercostal muscles occurred in all Io cases during inspiration, but two subjects showed a well developed independent rhythm during expiration.

These findings are illustrated in the following tracings: Figure 9 demonstrates the motor responses in the $3 \mathrm{rd}$, 6th and 8th interspaces to a single deep breath and a sustained deep breath. As shown, especially in 6th and 8th interspaces, the activity of the intercostals starts slightly earlier than that of the sternomastoid, in both the short single and the sustained deep breaths, and it is maintained throughout the latter. The test was carried out in a case of tetraplegia below C6 (J. H.) IO $\frac{1}{2}$ months after injury.

Figure Io shows the effects of progressively increased inspiration in a traumatic

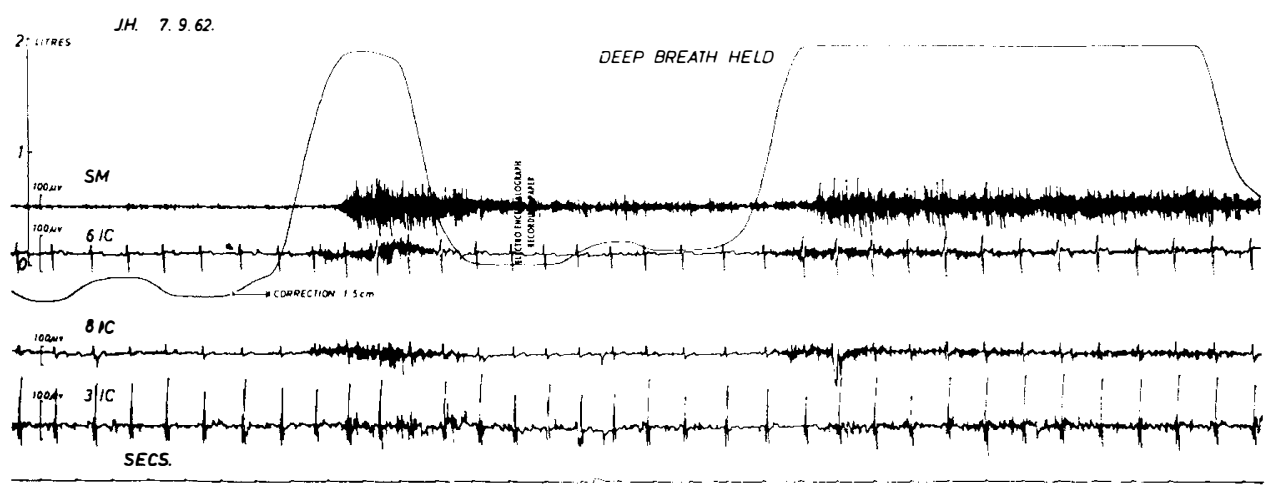

FIG. 9

J. H., IO $\frac{1}{2}$ months after complete lesion below C6. The activity in the $3 \mathrm{rd}$, 6th and 8 th interspaces is identical in timing and increases progressively in amplitude.

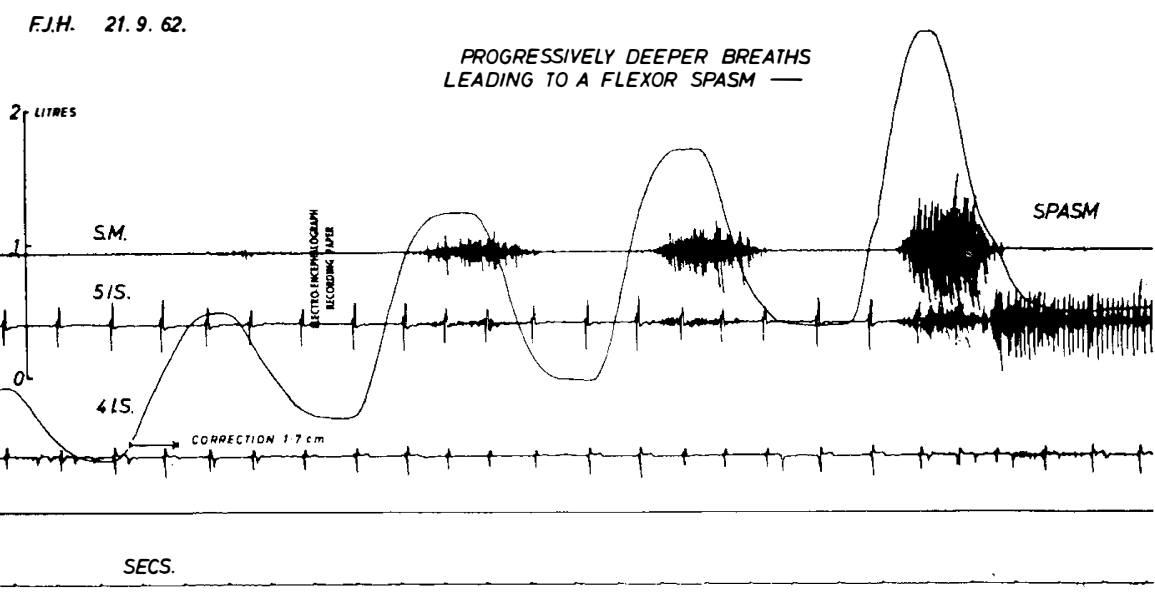

FIG. IO

F. J. H., 4 years 2 months after complete lesion below C5. No activity in 5 th interspace with breaths of less than I litre. With progressively larger breaths there was progressive increase in the activity until with the largest breath a flexor spasm developed. This spasm could also be seen in 4 th interspace which until then had been silent. 
tetraplegic below $\mathrm{C}_{5}$ examined four years and two months after injury. With a breath of up to I litre, no activity could be detected in the 5 th intercostal space, and the activity of the sternomastoid was minimal. However, with progressively deeper inspiration the activity of both the sternomastoid and 5th interspace also increased progressively, and the deepest breath elicited flexor spasms of the legs, affecting also the expiratory phase of the 5 th interspace. No activity was seen in this case in the $4^{\text {th }}$ interspace until the deepest breath was taken, which led to the flexor spasm of the leg.

Figure II illustrates a tetraplegic below C6, Io months after injury (Case R. H.). There were very marked motor responses in the 3 rd and especially the 5 th intercostal spaces to expiration which were in contrast to the much weaker inspiratory responses in these interspaces and were also in contrast to the profound inspiratory activity of the sternomastoid muscle in this case. Of special interest is the respiratory reflex activity of the abdominals (A. M.), which coincides with the inspiratory activity of both the sternomastoid and 3 rd and 5 th intercostal spaces.
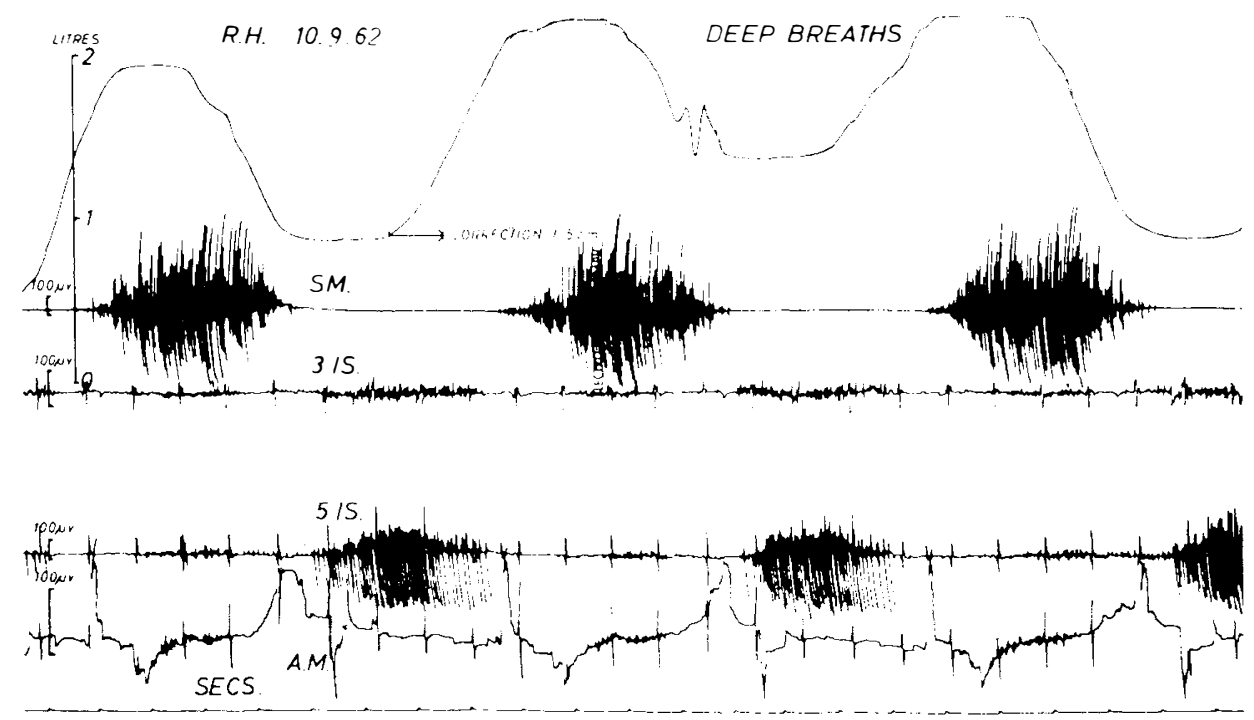

FIG. II

R. H., Io months after complete lesion below C6. Activity present during inspiration over 3rd and 5th interspaces and over abdominal muscles but much more marked separate expiratory rhythm in the intercostal spaces.

In Figure 12 (the same case as in Figure 10), the respiratory response of the abdominal muscles also coincides with the inspiratory activity of the sternomastoid and a maximal and sustained expiration reveals no activity of the abdominals, a finding which is in contrast to the normal expiratory response of the abdominals.

This is also shown in Figure 13 , illustrating the responses of the abdominal muscles (A. M.) during deep inspiration coinciding with those of the 7 th intercostal space (7 I. S.) and the sternomastoid (S. M.), in a tetraplegic below C6 examined three and a half years after injury (Case J. F. H.).

A detailed analysis of the respiratory responses of the intercostal muscles, in relation to the abdominal and sternomastoid muscles, was carried out in 14 tetra- 


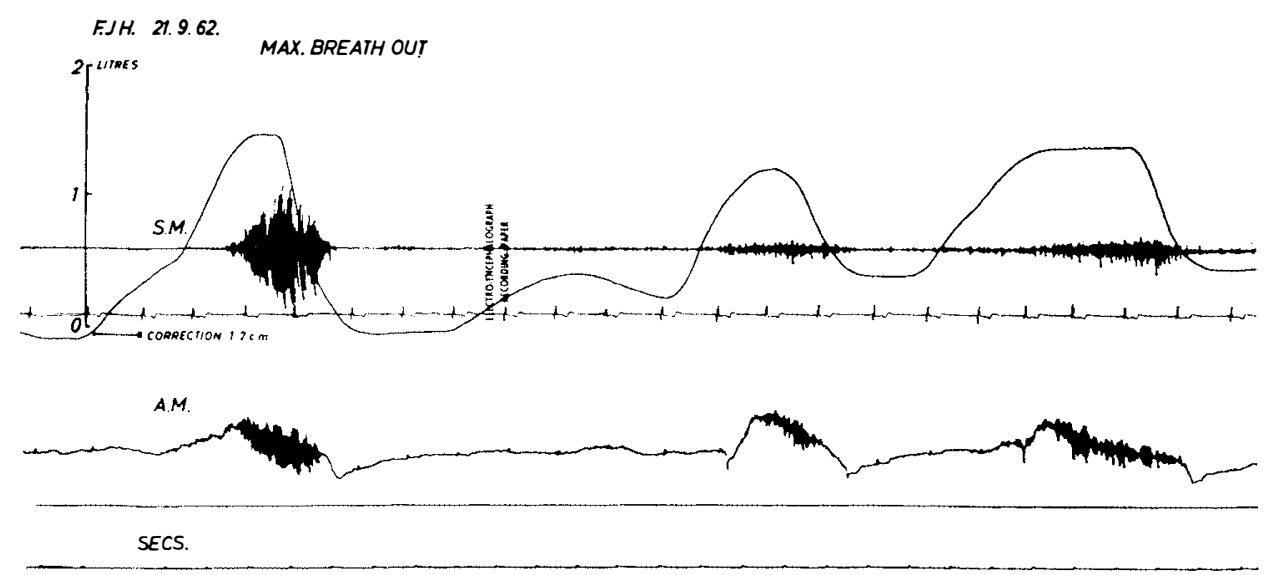

FIG. I2

F. J. H., same case as in Figure Io. No air can be expelled from the lungs beyond the end tidal point. The abdominal muscles do not contract during forced expiration. This is in complete contrast to the findings in normal subjects.

J.F.H. $\quad$ 5.9.62.

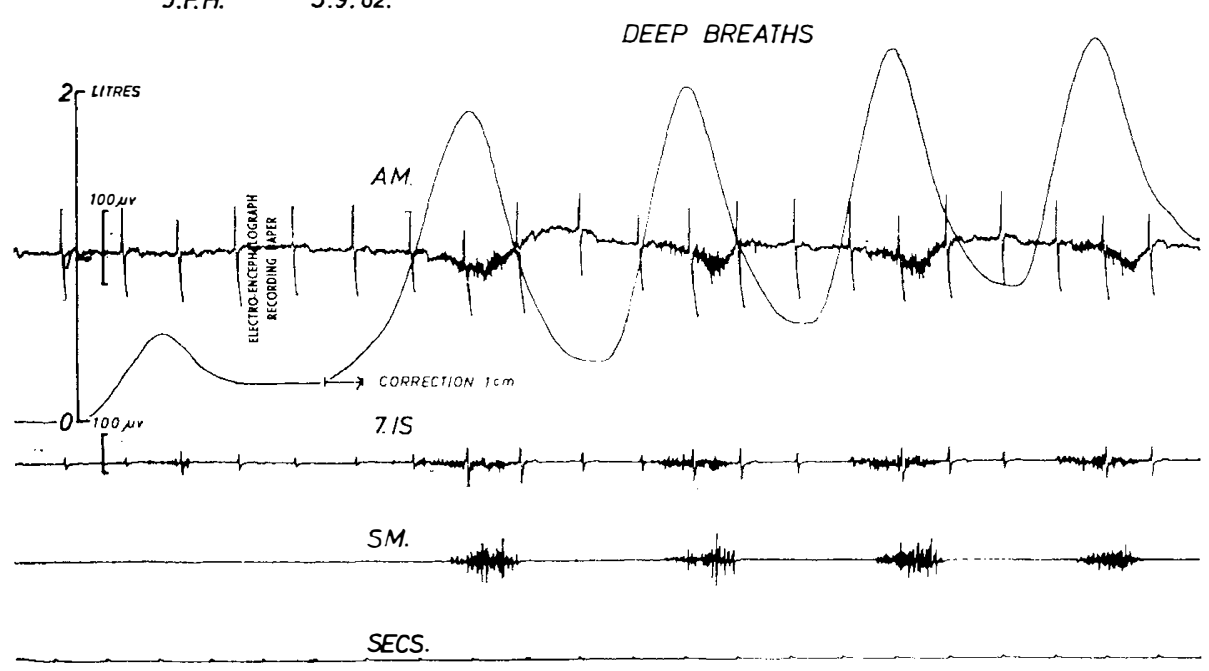

FIG. I3

J. F. H., $3 \frac{1}{2}$ years after complete lesion below C6. A.M. = abdominal muscles. Well-marked activity in abdominal muscles during inspiration, but this requires a breath of nearly 2 litres, whereas activity may be seen in 7 th interspace at considerably reduced amplification.

plegics; these comprised the patients from Group 2 and the patients from Group I in their late stages. It was found that quiet breathing did not evoke any response in the 2 nd, 3 rd and 4 th intercostal spaces. In only 4 of the I4 subjects did the sternomastoid show any response to quiet breathing, and in only I of I I subjects examined did the abdominals show any response to quiet breathing. On the other hand, deep breathing elicited definite responses not only in the lower intercostal 
spaces but also, though in the minority of cases, in the 2 nd, 3 rd and 4 th intercostal spaces.

The effect of a deep breath stimulus may not be confined to the intercostal and abdominal muscles but may spread over the whole reflexogenic zone below the cord transection. As shown in Figure Io, deep inspiration not only resulted in greatly increased reflex activity in the 5 th intercostal space but also showed definite response in the $4^{\text {th }}$ intercostal space and elicited generalised flexor spasms of the legs. Conversely, it was found that stimuli other than deep breathing, such as plantar stimulation, manipulation of the lower limbs or insertion of a urethral catheter, may evoke reflex responses of the intercostal and abdominal muscles. Figure I4 shows the reflex response of the 7 th intercostals to plantar stimulation.

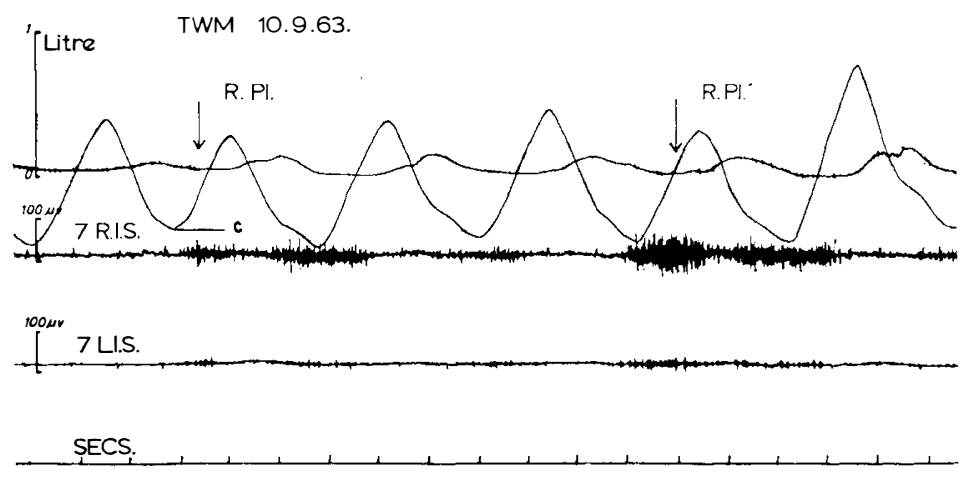

FIG. I4

T. W. M., 2 months after initially complete lesion below $\mathrm{C}_{4}$ on the left, $\mathrm{C}_{5}$ on the right. Diaphragm initially paralysed on left.

$\mathrm{R} . \mathrm{Pl}=$ right plantar stimulation. Well-marked activity over both 7 th right and left interspaces (7 R.I.S. and 7 L.I.S.) in response to this stimulation which persists into the next breath. Activity greatly reduced on the left although screening showed no appreciable difference in diaphragmatic function of the two sides.

However, these responses were found to be inconstant and variable in intensity; sometimes a deep breath could evoke activity of the intercostal muscles, while plantar stimulation was ineffective, but the reverse was also true.

\section{RELATIONSHIP BETWEEN INTERCOSTAL AND DIAPHRAGMATIC FUNCTION}

Special attention was paid to the reflex activity of the intercostals in relationship to the function of the diaphragm. In five tetraplegics, the diaphragm was examined by screening at various stages following injury; in two of them this was possible within the first eight days after injury. In two patients, the diaphragm was found contracting equally and symmetrically and there was no difference in the reflex function of the intercostal muscles. One subject (I. C.), with a complete tetraplegia below $\mathrm{C}_{5}$, examined one and a half months after the injury, showed a greatly reduced function of the right diaphragm, and the reflex activity of the intercostals in the 5 th to the 8 th right intercostal spaces was found to be greatly 
diminished. Figure 15 demonstrates the diminished electrical response in the 7 th intercostal space on the right, in comparison with the left during slight and deep inspiration.

Of special interest are three tetraplegics of this group with complete unilateral paralysis of the diaphragm; two of them were examined within the first few days after injury. One of them (T. W. M.), a man of 60, with a tetraplegia below $\mathrm{C}_{5}$ on the right and $\mathrm{C}_{4}$ on the left, showed at first a paralysis of the left diaphragm. Electromyographic examination four days after injury did not reveal any intercostal activity on the left; there was some activity on the right, but this was greatly reduced. Follow-up examinations were not possible until 20 days after injury. By that time the left diaphragm had recovered, as also had some sensibility in the paralysed part of the body. Electromyographically, there was some reflex function detectable in the 6th left intercostal space.

Figure I4 shows the reflex response of the 7 th intercostal muscles to plantar stimulation 7 I days after injury, showing definite though still reduced activity on the left side as compared with the right. There was no appreciable difference in the diaphragmatic function between the two sides.

In the second case (M. S. C.), a young man of 26 with an initially complete tetraplegia below $\mathrm{C}_{4}$ on the right and $\mathrm{C}_{5}$ on the left, $\mathrm{X}$-ray screening five days after injury revealed a paralysis of the right diaphragm. The vital capacity was then 0.4 litre. In this case, repeated electromyographic studies were carried out in the early stages after injury, starting on the 3 rd day. There was definite though greatly reduced intercostal reflex activity on the right side, as shown in Figure 16, demonstrating the findings on the 5 th day after injury. On the 2oth day, there was return of postural sensibility in the lower limbs, and X-ray re-screening on the 27th day revealed recovery of diaphragmatic function on the right. Electromyographically, there was no appreciable difference in the lower intercostal spaces between the two sides; as shown in Figure I7; the vital capacity had increased to I'I litres by the 9Ist day after injury.

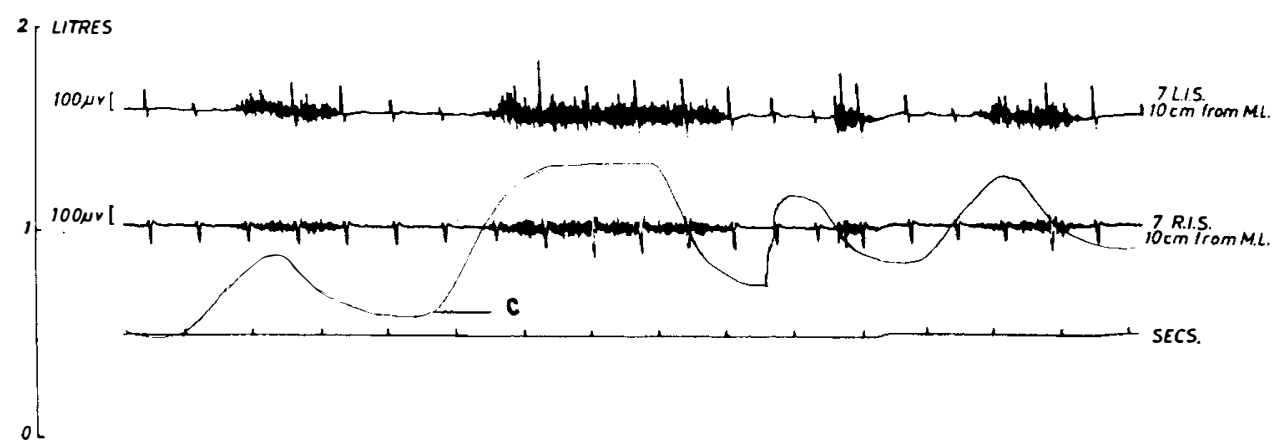

FIG. I5

I. C., I $\frac{1}{2}$ months after complete lesion below $\mathrm{C}_{5}$. Reduced activity in 7 th right interspace compared with 7 th left interspace (7 R.I.S., 7 L.I.S.). Screening showed greatly reduced function of right diaphragm.

The third case (B. Fa.) was a young man of I9 with a complete tetraplegia below $\mathrm{C}_{3}$ on the left and $\mathrm{C}_{5}$ on the right, whose condition was extremely serious during the first few weeks after injury. X-ray screening three and a half months 

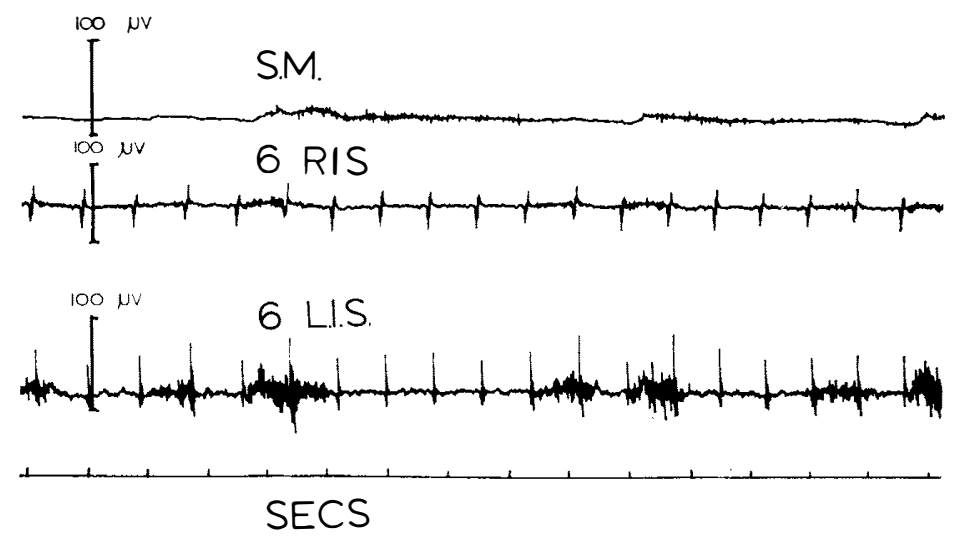

FIG. I6

M. S. C., 5 days after complete lesion below $\mathrm{C}_{4}$ on right and $\mathrm{C}_{5}$ on left. Screening at this stage showed paralysis of right diaphragm. Reduced activity in 6th right intercostal space as compared with left (6 R.I.S., 6 L.I.S.).

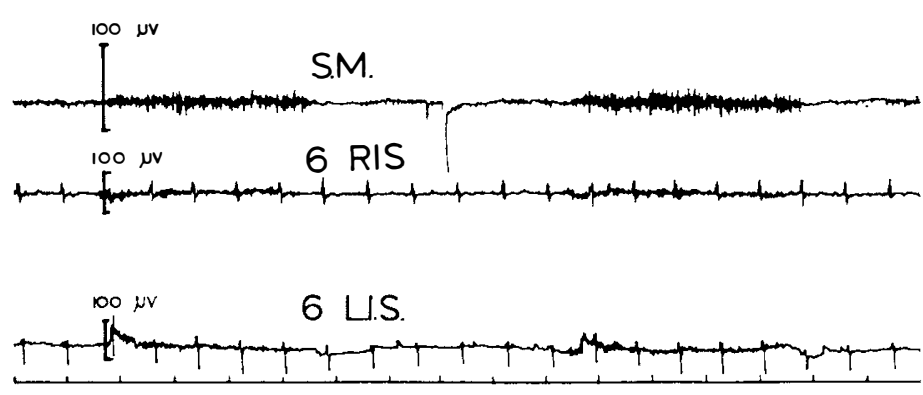

SECS

FIG. 17

M. S. C., 20 days after injury, no apparent difference between right and left sides. Right diaphragm recovering.

after injury showed complete paralysis of the left diaphragm (the left arm including deltoid, biceps, brachioradialis, as well as pectorals and latissimus dorsi was paralysed but sternomastoid and trapezius were of good power). However, electromyographic examination revealed definite though reduced intercostal activity on the left on inspiration. Quiet breathing evoked activity in the 7 th and 8th intercostal spaces on the left, while on the right the 6th intercostal space also responded. There was no response of the abdominal muscles. On deep inspiration, the activity of the intercostal muscles included not only the lower but also the 2nd and 3rd intercostal spaces on the left, although the response was greatly reduced as compared with the right side. There was also reflex response of the abdominal muscles at the height of inspiration. 
Figure I8 illustrates the electromyographic response from the 8th intercostal spaces during deep inspiration, demonstrating the definite though reduced reflex activity on the left. In this case, the sternomastoid had developed very marked compensatory respiratory function. Tracheostomy tube was removed six months after injury. Nine months after injury the paralysis of the left upper limb was unchanged and there was no significant change in the paralysis of the left diaphragm. The findings on vital capacity in this case will be described in the next paragraph.
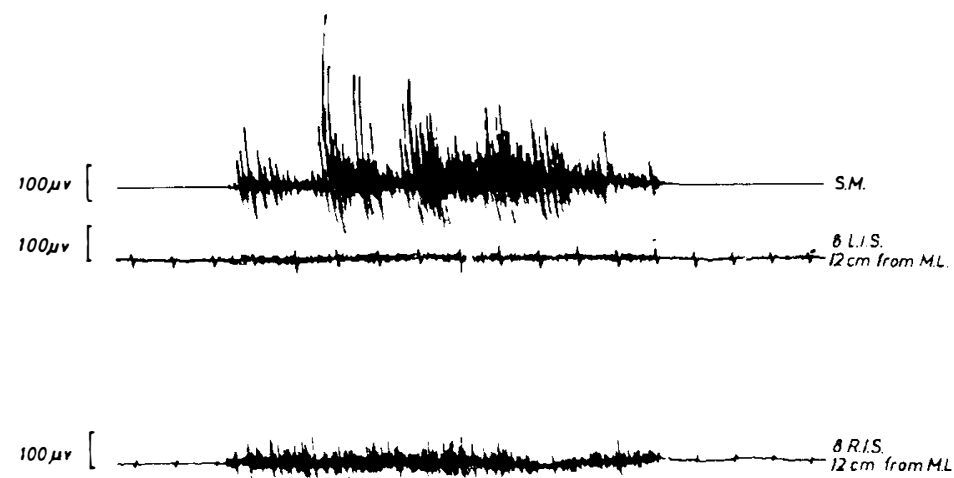

FIG. I 8

B. F., 4 months after complete lesion $\mathrm{C}_{3}$ on left and $\mathrm{C}_{5}$ on right. The diaphragm paralysed on the left. The asymmetry between the activity on 8th left interspace (8 L.I.S.) and 8th right interspace (8 R.I.S.) is most marked. In spite of this 8th L.I.S. showed definite though greatly reduced activity. Note the profound activity of sternomastoid.

\section{THE VITAL CAPACITY IN THE EARLY AND LATER STAGES OF TETRAPLEGIA}

Six patients were studied in this respect within the first eight days following complete physiological interruption of their cervical cord and followed up through later stages. The initial vital capacity, when corrected to B.T.P.S., was less than 2 litres in all cases. In those patients with involvement of the diaphragm, it was as low as $0.3-0.4$ litre. However, in all subjects the vital capacity increased in due course, as shown in Table I of the complete lesions, and the increase could be considerable. In the case of M. J. H. O., aged I8, the vital capacity increased from I to 3.3 litres over a period of I97 days. Of particular interest were the cases who at one stage or another showed a unilateral paresis or paralysis of the diaphragm. In the case of I. C., aged I9, who on X-ray screening I 3 days after injury showed a greatly impaired function of the right diaphragm-which however recovered within 36 days-the vital capacity rose from its initial value of 0.3 to 2 litres within I03 days. In case M. S. C., aged 26, who initially had a paralysis of the right diaphragm which recovered after 20 days, the vital capacity increased from 0.4 to I'I litres over a period of $9 \mathrm{I}$ days. In the case of B. Fa., aged I9, who was first 
examined electromyographically three and a half months after injury and where the X-ray screening revealed a complete paralysis of the left diaphragm, the vital capacity increased from 0.75 to $\mathrm{I} \cdot 2$ litres within 175 days. One hundred and ninety-five days after injury, vital capacity in the lying position was $I \cdot 4$ litres and in sitting 0.85 litre. At that time the patient was able to sit up to eight hours in his wheelchair. The latest test, 278 days after injury, showed a vital capacity of $I \cdot 7$ to 2 litres in the lying and $\mathrm{I} \cdot 3$ litres in the sitting position. He is now learning to control an electric typewriter with the aid of an electronic device, POSSUM, developed at this Centre (Maling \& Clarkson, I963) by using his mouth and blowing and sucking through a tube.

\section{DISCUSSION}

In accordance with Campbell's views (1958), surface electrodes were found preferable to concentric needles in our studies of reflex activity of the intercostal muscles in tetraplegia. Although needle electrodes, as shown in Figure 2, provided finer details for the identification and evaluation of electrical intercostal activity, the routine use of these needle electrodes presents several difficulties and disadvantages. Moreover, the present study was concerned with the detection of contractile activity within the bulk of the muscle tissue, for which surface electrodes are more satisfactory.

The outstanding feature in the results of our studies was the difference in the response of the paralysed intercostals to the stimulus of breathing in the immediate and later stages following traumatic tetraplegia. During the period of spinal shock, it was difficult to record action potentials from the intercostal muscles in response to the act of respiration. When found, they were of small amplitude and duration and consisted in irregular bursts to maximal inspiration only; moreover, they were only found anteriorly in the 6th, 7th and 8th intercostal spaces. Whether the complete lack of activity to respiratory stimuli above the 6th interspace in the early stages following tetraplegia is due only to the greater thickness of the tissues overlying the upper part of the chest or to other factors needs further study. It is known that such inactivity in this area also occurs in normal subjects: Campbell (I958) found that in normal females following radical mastectomy with removal of the pectoral muscles, and also in dyspnoeic patients with very thin chest walls, the patterns of activity in the intercostal muscles in both upper and lower intercostal spaces were essentially similar. Our findings in tetraplegics show that once the stage of spinal shock had subsided and full reflex activity of the isolated cord developed, the increase in the electrical response of the intercostals to the act of breathing was very conspicuous. Not only were the action potentials larger and the duration increased, but they could be elicited by smaller inspiratory stimuli and over a much larger area. Thus, intercostal activity was detectable as high as the second intercostal space and also over the abdominal muscles. Therefore, the recording of the reflex response of the intercostals was increasingly facilitated over the whole paralysed area, commensurate with the development of the reflex activity of the isolated cord. It has been shown that the act of breathing is as much an adequate afferent stimulus to the intercostals and abdominals as a stroke to the plantar surface of the foot for the skeletal muscles of the lower limbs, or the distension of the muscular wall of bladder and bowel a stimulus for their automatic evacuation. In this respect, it was interesting to find that once the reflex mechanism of the isolated cord has been fully developed, an afferent impulse as distant as that 
produced by plantar stimulation of the sole of the foot may elicit contractions in the intercostals and abdominal muscles. Conversely, a deep breath may evoke flexor spasms of the legs.

In discussing the mechanism of breathing in tetraplegic patients, it was found that the reflex activity of the intercostals showed a rhythm pattern in close relationship to the act of breathing; it commenced in either mid or late inspiration and lasted until early expiration. In two subjects a separate expiratory rhythm was detectable. The respiratory rhythm in cervical cord lesions below $\mathrm{C}_{5}$ was maintained in the early stages of tetraplegia almost entirely by the excursion of the diaphragm, which in these cases is the principal contributor to the force of inspiration. Wade and Gilson (195I) have calculated that the diaphragmatic movement is responsible for three-quarters of the ventilation in a full vital capacity. On descending during inspiration, the diaphragm separates passively the lower ribs on account of its anatomical attachment, thus causing a stretch effect on the intercostal muscles which acts as afferent stimulus of a stretch reflex. This stretch reflex increases in intensity commensurate with the subsiding of the spinal shock and the return of the reflex activity in the spinal cord. It is, therefore, not surprising that in a case of unilateral impaired diaphragmatic activity in cervical cord lesions, the reflex activity of the corresponding intercostal muscles is greatly reduced as shown in Figure 15. However, we found that even in the presence of complete hemidiaphragmatic paralysis the reflex activity of the intercostals is not abolished, as shown in two of our high cervical lesions; if, as shown in one case, it may at first be absent it will appear, however diminished, in due course. It may be noted that in cases with unilateral diaphragmatic paralysis the rhythmic respiratory movement is maintained by the function of the diaphragm of the other side, as well as by the function of accessory respiratory muscles, in particular sternomastoid. Moreover, it is likely that the elastic expansion of the lung itself during inspiration acts as a contributory force in stretching the intercostal spaces, thus serving as afferent stimulus to the reflex response of the intercostal muscles. One should, therefore, expect complete absence of reflex response in the intercostals if the unilateral diaphragmatic paralysis is associated with a haemothorax. So far, we have not had the opportunity to study this.

In the early stage of tetraplegia, the intensity of the compensatory respiratory function of the sternomastoid varies, and its development to full strength as an auxiliary force in the act of breathing (by exerting an upwards pull on the sternum and thus increasing the antero-posterior diameter), may take some time and may need systemic exercises. This auxiliary force, also assisted by the trapezius and the scaleni, can be considerable, and one of us (L. G.) has shown that the sternomastoid may develop a profound hypertrophy. No doubt the diaphragm, in conjunction with these auxiliary respiratory muscles, is the main contributor to the restoration of the initially greatly reduced vital capacity of the lungs. However, our findings indicate that the co-ordinated reflex function of the intercostal muscles resulting from the rhythmic movements of the chest also plays a part in this process of respiratory recovery. The intercostal muscles regain their tone once the spinal shock has subsided and, in due course help to restore (by their reflex contractions especially during inspiration) the tension and rigidity of the intercostal spaces essential for a more powerful function of the diaphragm; they thus contribute to a better ventilation of the lungs which enables the tetraplegic in later stages to lead a more active life. 


\section{SUMMARY}

In 19 traumatic tetraplegics following fracture dislocation of the cervical spine, the intercostal and abdominal muscles were studied electromyographically. The patients were divided into three groups:

I. Patients examined first during the stage of spinal shock and followed up until full reflex activity of the isolated cord developed.

2. Patients studied in later stages only (three months to more than four years after injury).

3. Patients with unilateral paralysis of the diaphragm.

During the stage of spinal shock, action potentials of the intercostal muscles in response to the act of breathing were irregular and of small amplitude and duration; they were detectable in the lower intercostal spaces only.

In the stage of fully developed reflex activity of the spinal cord, the electrical response of the intercostals was very striking over a much wider area. Details of their reflex activity are described.

Unilateral paralysis of the diaphragm greatly reduced but did not abolish reflex function of the intercostals.

The significance of the reflex activity of the intercostal muscles is discussed.

\section{ACKNOWLEDGEMENT}

This study was carried out with the aid of grants from the Medical Research Council and the Polio Research Fund. The authors are also indebted to Professor E. Neil of the Department of Physiology, Middlesex Hospital, for kindly lending us the Ediswan electroencephalograph machine. One of us (J. R. S.) is grateful to Dr. E. J. M. Campbell for instruction in his techniques.

\section{RÉSUMÉ}

Nous avons etudié 19 cas de tétraplegie traumatique, et nous avons examiné leurs muscles intercostaux et abdominaux avec l'aide de l'electromyographie. Nous avons groupé ces malades:

I. Des malades examinés pendant leur premier état de choc spinal qui furent observés jusqu'a ce que l'activité réflexe de la moëlle épinière isolée se dévelopa.

2. Des malades chroniques examinés seulement après trois mois ou jusqu'a quatre ans après leur accident.

3. Des malades avec paralysie unilaterale du diaphragme.

Pendant leur choc spinal, l'activité électrique des muscles intercostaux pendant la respiration fut irrégulière et montra une petite amplitude et duration. Cette activité fut trouvée seulement dans les muscles intercostaux de la partie inférieure du thorax.

Chez les malades chroniques, la réponse électrique des muscles intercostaux fut très frappant dans une partie plus grande. Les détails de l'activité réflexe sont décrivés.

Chez les malades avec paralysie unilatérale du diaphragme la réponse électrique etait très diminuée mais elle n'etait pas absente.

L'importance de l'activité réflexe des muscles intercostaux est discutée.

\section{ZUSAMMENFASSUNG}

An I9 Patienten mit Luxationsfrakturen der Halswirbelsäule und Tetraplegie wurden die Intercostal—und Bauchmuskeln elektromyographisch untersucht. Die Patienten wurden in 3 Gruppen aufgeteilt:

I. Patienten, die zuerst während der Phase des spinalen Schocks untersucht und dann nachuntersucht wurden, bis sich die Reflexe des isolierten Rückenmarks voll entwickelt hatten. 
2. Patienten, die erst 3 Monate bis 4 Jahre nach dem Unfall untersucht wurden.

3. Patienten mit einseitiger Zwerchfellähmung.

Während der Phase des spinalen Schocks wurden nur schwache, kurzfristige und unregelmässige Aktionspotentiale der Intercostalmuskeln als Reaktion auf die Atmung gefunden und zwar nur in den unteren Intercostalräumen.

In der Phase voll entwickelter Reflexaktivität des Rückenmarks war die elektrische Reaktion der Intercostalmuskeln auffallend kräftig in einem viel grösseren Bezirk.

Einseitige Zwerchfellähmung verringerte die Reaktion erheblich, hob sie aber nicht auf. Die Bedeutung der Reflexaktivität der Interkostalmuskeln wird erörtert.

\section{REFERENCES}

Anderson, F. M. \& Lindsley, D. B. (I935), F. Lab. clin. Med. 20, 623.

Bronk, D. W. \& Ferguson, L. K. (I935). Amer. K. Physiol. 110, 700.

Cameron, G. S., Scott, J. W., Jousse, A. T. \& Botterell, E. H. (I955). Ann. Surg. I41, $45 \mathrm{I}$.

Campbell, E. J. M. (1952). F. Physiol. I17, 222.

Campbell, E. J. M. (I955). F. Physiol. 129, I2.

CAMPBell, E. J. M. (1958). The Respiratory Muscles. London: Lloyd Luke.

Campbell, E. J. M. \& Green, J. H. (1953). F. Physiol. 120, 409.

Gilliatt, R. W., Guttmann, L. \& Whitteridge, D. (1947). F. Physiol. 107, 67.

Grossiord, A., Jaeger-Denavit \& Miranda, Anamaria C. (1963). La Semaine des Hôpitaux, p. 663.

GutTMANN, L. \& BeLl, D. T. (1958). Suspension Therapy, pp. 147-169. ed. Hollis, M. \& Roper, M. H. S. London: Tindall.

Hemingway, A., Bors, E. \& Hobby, R. P. (1958). F. clin. Invest. 37, 775.

Maling, R. G. \& Clarkson, D. C. (I963). Paraplegia, I, I6I.

Talbot, H. S., Rocco, A. G. \& Conroy, M. E. (1957). In Proceedings of the 6th Annual Clinical Paraplegia Conference, p. 20. Washington: American Veterans Administration.

WaDE, O. L. \& Gilson, J. C. (I95I). Thorax, 6, I03.

Wingo, G. F. (1957). In Proceedings of the 6th Annual Clinical Paraplegia Conference, p. 23. Washington: American Veterans Administration. 